\title{
Atividade antioxidante do ácido hialurônico extraído da crista de frango
}

\author{
Antioxidant activity of hyaluronic acid extracted from chicken crest \\ Claudia Severo da Rosa ${ }^{*}$ Solange Cristina Hoelzel ${ }^{\text {II }}$ Vanessa Bordin Viera ${ }^{\text {II }}$ \\ Pedro Manique Barreto ${ }^{I}$ Luiz Henrique Beirão ${ }^{\mathrm{I}}$
}

\section{RESUMO}

O ácido hialurônico (AH) é uma macromolécula com importância na área médica, na área farmacêutica e na indústria de cosméticos. O cordão umbilical e a crista de galo são os tecidos mais ricos neste polissacarídeo. O Brasil é um dos principais exportadores de frango do mundo; assim, o aproveitamento das cristas dos animais abatidos para a obtenção de $\mathrm{AH}$ se mostra particularmente atraente. Este trabalho teve como objetivos fazer a extração do AH da crista de frango e determinar a atividade antioxidante in vitro. Cristas de frangos secas e delipidadas foram submetidas à digestão proteolítica e posteriormente à precipitação com cloreto de cetilpiridinio (CPC). A atividade antioxidante foi determinada pelo método de seqüestro do radical 2,2 - difenil 1-picrilhidrazil (DPPH). A concentração de glicosaminoglicanos (GAGs) na crista de frango é de $14,9 \mu \mathrm{g}$ de ácido hexurônico $/ \mathrm{mg}$ de tecido seco e o AH extraído apresentou ótima atividade antioxidante in vitro. Desse modo, o AH pode ser aproveitado como um resíduo das indústrias de processamento de frangos.

Palavras-chave: cristas de frangos, glicosaminoglicanos, extração.

\section{ABSTRACT}

The hyaluronic acid (HA) is an important macromolecule in medical and pharmaceutical areas as well as in the cosmetics industry. The umbilical cord and the chicken crest are two of the richest tissues in this polysaccharide. Since Brazil is one of the main chicken exporters in the world, the utilization of crests from slaughtered animals to obtain HA is particularly attractive. The present research aimed to extract hyaluronic acid (HA) from the crest and determine its antioxidant activity in vitro. Dry and delipidated chicken crest underwent proteolytic digestion and subsequent precipitation with cetylpyridinium chloride (CPC). Antioxidant activity was determined by the 2,2-Diphenyl-1-picrylhydrazyl (DPPH) method. The glycosaminoglycans (GAG) concentration in the chicken crest was $14.9 \mu \mathrm{g}$ of hexuronic acid /mg of dry tissue and the extracted HA presented great antioxidant activity in vitro. Thus, HA may be used as a sub-product of poultry processing industries.

Key words: chicken crest, glycosaminoglycans, extraction.

\section{INTRODUÇÃO}

A avicultura industrial é uma das atividades agrícolas mais desenvolvidas no mundo. Impulsionada sobretudo pela necessidade de utilização de proteína de origem animal na dieta humana, a produção avícola no Brasil representa uma das mais importantes cadeias produtivas. Em 2002, a produção brasileira de carne de frango foi de 7,449 milhões de toneladas, o que representa um crescimento de $13,5 \%$ em relação ao ano de 2001 (NUNES et al., 2005). Em 2007 foram produzidas 8,988 milhões de toneladas de carne de frango (IBGE, 2008). Entre os países que se destaca no setor, o Brasil ocupa o terceiro lugar no mercado mundial de produção de carne de frango. Para que o setor mantenha o sucesso, é preciso investir em produtividade a baixo custo. Além disso, é necessário atenção especial à questão ambiental, destacando-se a importância do aproveitamento dos resíduos da indústria avícola (NUNES et al., 2005).

A crista de frango é rica em $\mathrm{AH}$ e, sendo um resíduo, é desprezada junto com a cabeça para a graxaria. IPrograma de Pós-graduação em Ciências dos Alimentos, Universidade Federal de Santa Catarina (UFSC), 88034-001, Florianópolis,
SC, Brasil. Email: claudiasr37@yahoo.com.br. *Autor para correspondência.

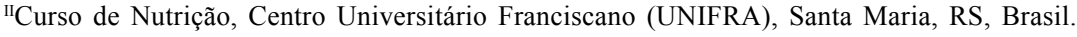


$\mathrm{O}$ AH é constituído exclusivamente por unidades dissacarídicas repetidas contendo $\mathrm{N}$-acetilglicosamina e ácido D-glicurônico. Embora o AH tenha a estrutura química menos complexa de todos os glicosaminoglicanos, as cadeias podem atingir massas molares de $10^{5}-10^{7} \mathrm{Da}$ e possuem importantes aplicações nas áreas médica, farmacêutica e cosmética. OAH é usado no tratamento de doenças degenerativas e inflamatórias das articulações dos ossos, na reposição do fluído sinovial e na liberação de agentes quimioterápicos em implantes cirúrgicos, como meio hidratante e como sistema para encapsulação e liberação controlada de fármacos e cosméticos (OGRODOWSKI, 2006). Ele também é aplicado em lentes de contato (Beek et al., 2008) e em aplicações vasculares, como um copolímero com propriedades antitrombóticas (XU et al., 2008).

O fenômeno da longevidade, tanto no Brasil como nos demais países do mundo, foi alavancado pelas mudanças nos estilos de vida. A participação de fatores ambientais, os processos tecnológicos e científicos desenvolvidos na medicina, associados à melhora nas condições socioeconômicas mesmo nos países em desenvolvimento, foram e permanecem sendo os fatores determinantes de aumento de expectativa de vida (MOI, 2004).

O aumento acentuado do número de idosos, particularmente nos países em desenvolvimento, como o Brasil, trouxe diversas conseqüências para a sociedade. A população idosa brasileira está mais sujeita a problemas de saúde, com o surgimento de enfermidades crônicas que acarretam baixa letalidade $\mathrm{e}$ às vezes alto grau de incapacidade, como é o caso da osteoartrite (MOI, 2004).

Preparações de AH intra-articulares são usadas para aumentar a viscosidade do líquido sinovial, que é reduzido em pacientes com osteoartrite (PEREIRA, 2002).

Vários autores sugerem que alguns GAGs possuem propriedade antioxidante, como o $\mathrm{AH}$ e o sulfato de condroitina, que inibem a peroxidação lipídica por quelarem metais de transição como o $\mathrm{Cu}^{2+}$ e o $\mathrm{Fe}^{2+}$ (ALBERTINI et al., 2000).

O aumento dos níveis de GAGs no plasma pode representar uma resposta biológica para produção de radicais livres. $\mathrm{O}$ uso desses componentes como agentes terapêuticos mostra resultados positivos em modelos animais experimentais (FRASER et al., 1997).

Este trabalho teve como objetivos extrair o AH da crista de frango e determinar a atividade antioxidante in vitro.

\section{MATERIAL E MÉTODOS}

As cristas usadas neste experimento foram fornecidas pelo frigorífico Pena Sul de Caxias do Sul, Rio Garnde do Sul (RS). As cristas foram coletadas na linha de abate, sendo $50 \%$ das cristas de frangos machos e $50 \%$ de fêmeas com idade de 48 dias. As cristas foram transportadas congeladas até Santa Maria-RS e permaneceram congeladas a $-18^{\circ} \mathrm{C}$ até o início do experimento. As análises foram realizadas no laboratório de Tecido Conjuntivo da UFRJ e no laboratório de Bromatologia do Centro Universitário Franciscano.

Extração dos glicosaminoglicanos totais das cristas de frango

As cristas foram trituradas e colocadas em acetona para desidratação e delipidação. Posteriormente elas foram secas, pesadas e agrupadas, sendo utilizado em torno de $100 \mathrm{~g}$ para cada extração (n =3). Depois disso, foi realizada delipidação em solução clorofórmio/metanol $(2: 1, \mathrm{v} / \mathrm{v})$ por $24 \mathrm{~h}$ a $25^{\circ} \mathrm{C}$. Os tecidos foram secos e hidratados em tampão de digestão (acetato de sódio $100 \mathrm{mM} \mathrm{pH}=5,0$, cisteína 5,0mM e EDTA dissódico 5,0mM) na proporção de 2,0mL de tampão para $100 \mathrm{mg}$ de tecido seco. Após hidratação por $24 \mathrm{~h} \mathrm{a} 4^{\circ} \mathrm{C}$, os tecidos receberam solução de papaína (20 $\left.\mathrm{mg} \mathrm{mL}^{-1}\right)$, preparada na solução tampão de digestão descrita anteriormente, numa proporção de $0,5 \mathrm{~mL}$ para $100 \mathrm{mg}$ de tecido seco. Posteriormente, os tecidos foram incubados por $24 \mathrm{~h} \mathrm{a} 60^{\circ} \mathrm{C}$ e centrifugados a 3200rpm por $30 \mathrm{~min}$ e foi retirado o sobrenadante. O precipitado foi submetido à nova incubação com papaína, sob as mesmas condições descritas anteriormente. Em seguida, foi adicionado ao sobrenadante cloreto de cetilpiridínio (CPC) $10 \%$, numa proporção de $0,2 \mathrm{~mL}$ para $100 \mathrm{mg}$ de tecido seco, que foi deixado em repouso por $24 \mathrm{~h}$ a $25^{\circ} \mathrm{C}$. A amostra foi centrifugada, o sobrenadante descartado e o pellet lavado com $3,0 \mathrm{~mL}$ de solução de $\mathrm{NaCl} 2,0 \mathrm{M}$ e etanol absoluto (100:15, v/v). Nessa amostra, foram adicionados dois volumes de etanol absoluto. Depois, ela foi deixada em repouso por $24 \mathrm{~h}$ a $-16^{\circ} \mathrm{C}$. Seguiu-se centrifugação, descarte do sobrenadante e lavagem do pellet uma vez com $10 \mathrm{~mL}$ de etanol $80 \%$. Seguiu-se nova centrifugação e secagem do pellet por $24 \mathrm{~h}$ a $25^{\circ} \mathrm{C}$ (CARDOSO et al., 1992).

Dosagem de ácido hexurônico (método de Carbazol)

A concentração do ácido hexurônico da solução contendo $\mathrm{AH}$ foi determinada por meio de método químico, utilizando o reagente colorimétrico Carbazol (DISCHE, 1946). Esse método baseia-se no 
desenvolvimento de cor pela ação de compostos orgânicos como o reagente Carbazol. A dosagem de ácido hexurônico foi realizada com $200 \mu \mathrm{L}$ de amostra, aos quais se adicionou $1,0 \mathrm{~mL}$ de ácido sulfúrico com borato. Despois disso, a amostra foi aquecida por $10 \mathrm{~min}$ a $100^{\circ} \mathrm{C}$ e resfriada à temperatura ambiente e recebeu $40 \mu \mathrm{L}$ de carbazol. Logo depois, ela foi aquecida novamente por $12 \mathrm{~min}$ a $100^{\circ} \mathrm{C}$ e resfriada à temperatura ambiente. A leitura foi realizada no espectrofotômetro em comprimento de onda de $525 \mathrm{~nm}$ (Ultrapesc 3100 pro - Amersham Biosciences). A concentração do AH foi determinada por meio de uma curva de calibração previamente construída com o $\mathrm{AH}$ padrão (Vinovo Biochemistry) tomado como referência. A curva padrão foi feita com diferentes concentrações de glicuronolactona $\left[0,5 \mathrm{mg} \mathrm{mL}^{-1}\right]: 5,0-15 \mu \mathrm{g}$. A concentração de $\mathrm{AH}$ foi calculada a partir do conteúdo de ácido hexurônico x 1,95 (SWANN, 1968).

Fracionamento dos glicosaminoglicanos

Os glicosaminoglicanos da crista de frango foram aplicados em uma coluna de troca iônica Mono Q (HR 5/5) acoplada a um sistema de Fast Protein Liquid Chromatography (FPLC) (Amersham Pharmacia Biotech), equilibrada com tampão Tris- $\mathrm{HCl} 20 \mathrm{mM}, \mathrm{pH}$ 8,0 , e submetidos a um gradiente linear de $\mathrm{NaCl}(0$ a $1,5 \mathrm{M})$ no mesmo tampão. O fluxo da coluna foi de $1 \mathrm{~mL}$ $\min ^{-1}$ e foram recolhidas frações de $0,5 \mathrm{~mL}$. As mesmas foram avaliadas pelo conteúdo de ácido hexurônico e pela metacromasia produzida pelos glicosaminoglicanos sulfatados na presença de azul de dimetilmetileno (DMB). A concentração de sal foi estimada pela condutividade.

Determinação da atividade antioxidante - Método de captação do radical DPPH (2,2 - difenil 1-picrilhidrazil)

A atividade antioxidante foi determinada pela redução do radical estável DPPH (2,2 - difenil 1picrilhidrazil) e pelos antioxidantes presentes na amostra, utilizando-se concentrações finais de 500, 250, $100,50,10 \mu \mathrm{g} \mathrm{mL}^{-1}$ em solução aquosa. Em um tubo de ensaio, foi adicionado um volume de $2,5 \mathrm{~mL}$ da amostra e em seguida adicionou-se $1,0 \mathrm{~mL}$ de solução de DPPH $0,3 \mathrm{mM}$ em etanol. Após 30 minutos, foram realizadas as leituras das amostras em absorbância de $518 \mathrm{~nm}$. A solução de DPPH (1,0mL; 0,3mM) mais etanol (2,5mL) foi usada como controle (KNATT et al., 2008). A atividade antioxidante foi calculada com o auxílio da fórmula (1).

$\%$ seqüestro de radicais livres $=100-\left[\left(\mathrm{A}_{\mathrm{A}}-\mathrm{A}\right) / \mathrm{A}_{\mathrm{C}}\right] \times 100$ Onde: $\mathrm{A}_{\mathrm{A}}=$ absorbância da amostra

$\mathrm{A}_{\mathrm{C}}=$ absorbância do controle
Análise estatística

Para uma análise comparativa da atividade antioxidante do $\mathrm{AH}$ extraído de cristas de frango e do AH padrão, aplicou-se Análise de Variância em um nível de significância de $1 \%$, com auxílio do software Microsoft Office Excel (BRAULE, 2001).

\section{RESULTADOS E DISCUSSÃO}

Concentração dos GAGs nas cristas de frango

O material seco e delipidado obtido das cristas de frango correspondeu a $\cong 16 \%$ do peso líquido das mesmas. A concentração dos glicosaminoglicanos totais foi de 14,9 $\mu \mathrm{g}$ de $\mathrm{AH} \mathrm{mg}^{-1}$ de tecido seco. O valor é bem inferior ao relatado por NAKANO \& SIM (1989; 1991), de 42,1 $\mu \mathrm{g}$ ácido hexurônico $\mathrm{mg}^{-1}$ de tecido seco. Entretanto, nesse estudo os glicosaminoglicanos totais das cristas foram extraídos de animais de 52 semanas (364 dias), enquanto que no presente estudo os animais tinham 48 dias, portanto, animais bem mais jovens. NAKANO et al. (1994) reportaram que o teor de ácido hexurônico no tecido vermelho situado abaixo do bico de galos de 52 semanas é de $19,1 \mu \mathrm{g} \mathrm{mg}^{-1}$ de tecido seco, valor próximo ao encontrado neste estudo para as cristas de frango.

Segundo NAKANO \& SIM (1991), as cristas de animais mais velhos e animais machos possuem quantidades maiores de ácido hialurônico. Além disso, o escaldamento das cristas pode diminuir a concentração de AH e o método de extração também pode influenciar sua obtenção (SZIRMAI, 1956; BALAZS et al., 1958; SWANN, 1968). Mesmo assim, em função da quantidade de frangos abatidos nos frigoríficos, a extração do $\mathrm{AH}$ pode vir a ser compensadora.

O extrato de GAG total das cristas de frango foi fracionado em uma coluna Mono-Q. Pode-se observar (Figura 1) um pico majoritário, correspondendo a $\cong 90 \%$ do total de ácido hexurônico da amostra, eluindo com $\sim 400 \mathrm{mM}$ de $\mathrm{NaCl}$, e não exibindo metacromasia significativa. Essas propriedades são características do $\mathrm{AH}$ quando aplicado nesta coluna (CARDOSO et al., 1992). Pôdese também observar uma fração exibindo propriedade metacromática, eluída com concentração de $\mathrm{NaCl}$ superior a $1 \mathrm{M}$, indicando a presença de GAGs sulfatados na amostra analisada. As cristas obtidas de animais de 48 dias apresentaram $14,9 \mu \mathrm{g}$ de ácido hexurônico/mg de tecido seco. Assim, a quantidade obtida de AH é calculada multiplicando o valor encontrado de ácido hexurônico por 1,95 e considerando um rendimento de $90 \%$, que resulta em $26,15 \mu \mathrm{g}$ de ácido hialurônico $\mathrm{mg}^{-1}$ de tecido seco. Em 


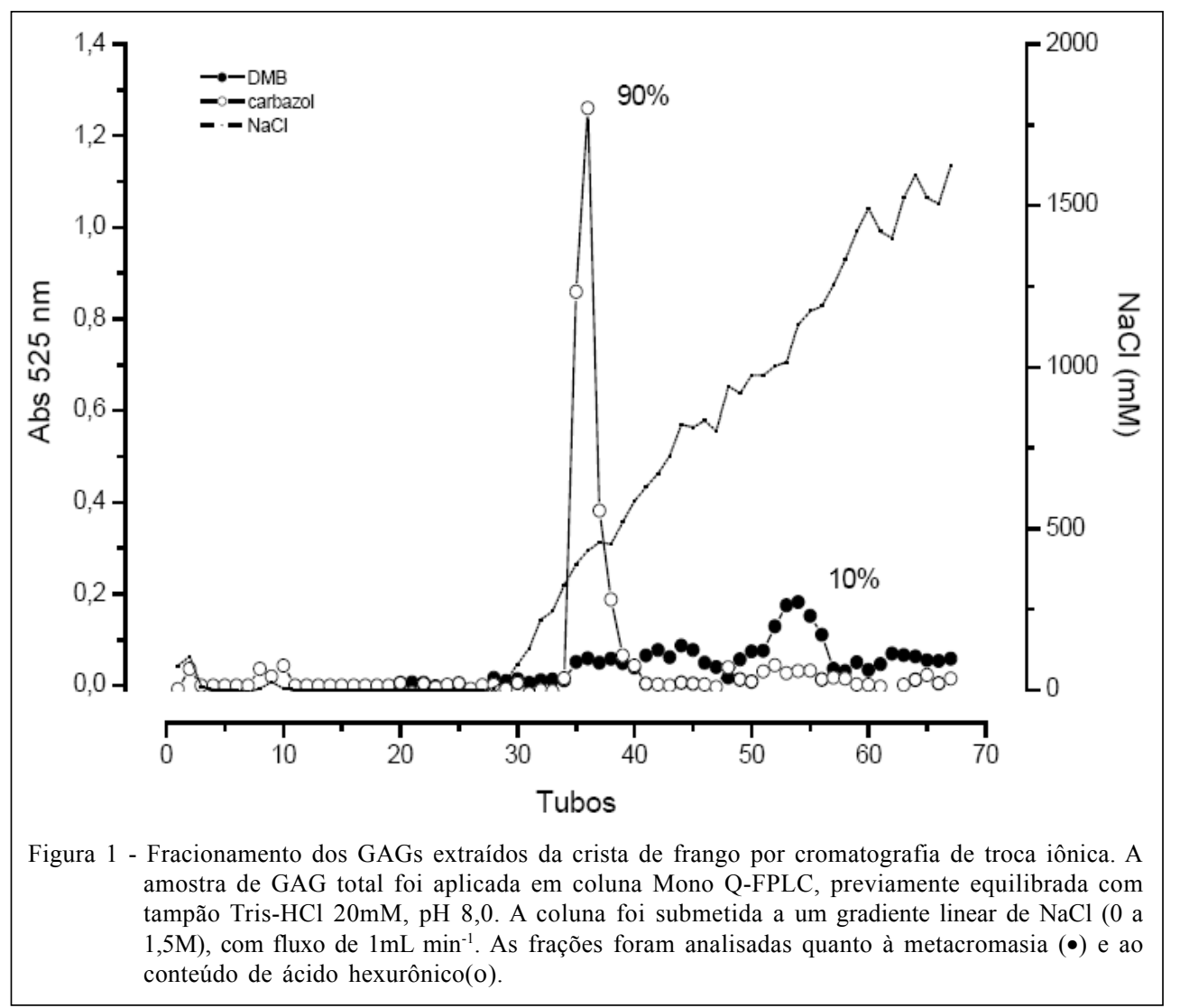

2005, foram abatidas 17.566 .405 cabeças dia ${ }^{-1}$ de frangos no Brasil, segundo dados da Associação Brasileira dos Produtores e Exportadores de Frangos (ABEF), União Brasileira de Avicultura (UBA), Associação Fluminense de Avicultura (AFA) (OLIVO \& OLIVO, 2006). Levandose em conta que cada crista pesa em média $3 \mathrm{~g}$, são aproximadamente 52,7 toneladas apenas deste resíduo por dia que poderia ser utilizado para extração de aproximadamente 1,4 toneladas de AH. Vale ressaltar que todo o AH usado no Brasil é importado a um custo de US\$ 65,00 100 $\mathrm{mL}^{-1}$ (OGRODOWSKI, 2006).

\section{Atividade antioxidante}

A capacidade de seqüestrar o radical DPPH pelo $\mathrm{AH}$ extraído da crista de frango encontra-se na figura 2. O AH extraído da crista de frango possui forte atividade para seqüestrar o radical $\mathrm{DPPH}$, não apresentando diferença significativa $(\mathrm{P}>0,01)$ entre $\mathrm{o}$ $\mathrm{AH}$ extraído e o $\mathrm{AH}$ padrão (Figura 2). O efeito seqüestrante do $\mathrm{AH}$ extraído variou de $83,9 \%$ na concentração de $10 \mu \mathrm{g} \mathrm{mL}^{-1}$ a $87,3 \%$ na concentração de $500 \mu \mathrm{g} \mathrm{mL}^{-1}$ e o $\mathrm{AH}$ padrão variou de $77,63 \%$ na concentração de $10 \mu \mathrm{g} \mathrm{mL}^{-1}$ a $85,1 \%$ na concentração de $500 \mu \mathrm{g} \mathrm{mL} \mathrm{m}^{-1}$.
Esses valores mostram que o AH extraído pode ser usado como um antioxidante natural. Além de seu uso na medicina, pode ser usado pela indústria alimentícia como um ingrediente natural com propriedade antioxidante.

Estudos realizados por Campo et al. (2004) mostraram a atividade antioxidante do $\mathrm{AH}$ e C4S (4sulfato de condroitina) em ratos induzidos com $\mathrm{CCl}_{4}$, provocando fibrinogênese. $\mathrm{O} \mathrm{AH}$ e o $\mathrm{C} 4 \mathrm{~S}$ em altas concentrações $\left(25 \mathrm{mg} \mathrm{mL}^{-1}\right)$ agiram como potentes antioxidantes, atenuando significativamente a peroxidação lipídica. A provável hipótese sobre o mecanismo pelo qual o $\mathrm{AH}$ e o $\mathrm{C} 4 \mathrm{~S}$ reduzem radicais livres está baseada nas suas estruturas. Os dois polímeros apresentam estruturas com ligações cruzadas, com grupos carboxílicos em algumas posições. Esses grupos carboxílicos podem interagir com íons metálicos como $\mathrm{Cu}^{2+}$ ou $\mathrm{Fe}^{2+}$, que são responsáveis pela iniciação da reação de Fenton. Essas moléculas podem funcionar como quelantes de metais.

AI et al. (2007) determinaram a atividade antioxidante do chitosan isolado de larvas de moscas in vitro pelo método de DPPH em várias concentrações e verificaram que o chitosan possui capacidade de 


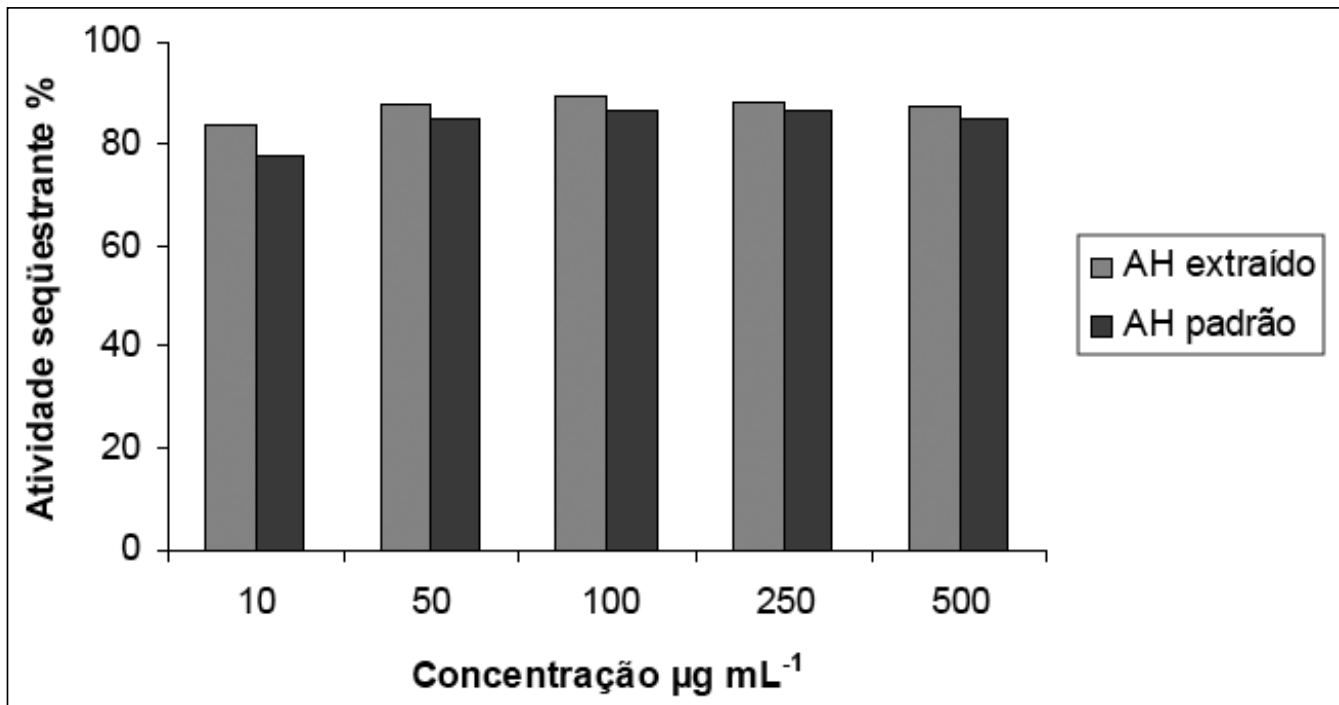

Figura 2 - Capacidade de seqüestrar radicais livres do ácido hialurônico, extraído da crista de frango e do ácido hialurônico padrão.

seqüestrar radicais livres. $\mathrm{O}$ efeito do chitosan sobre o radical livre DPPH foi de $57,1 \%$ na concentração de $0,5 \mathrm{mg} \mathrm{mL}^{-1}$, valor inferior ao encontrado neste experimento pelo ácido hialurônico na menor concentração $\left(10 \mu \mathrm{g} \mathrm{mL}^{-1}\right)$, que foi de $83,94 \%$.

Pesquisas recentes realizadas por KNATT et al. (2008) mostraram que a combinação de chitosan e extrato de hortelã, na mesma proporção, agem como potente antibacteriano e agente antioxidante e pode ser usada para preservar e aumentar o tempo de vida de prateleira de carnes e produtos cárneos. Como o chitosan e o AH são polímeros com estruturas semelhantes, é provável que o $\mathrm{AH}$ adicionado a produtos cárneos possa também agir como antioxidante.

\section{CONCLUSÕES}

O aproveitamento das cristas de frango pela indústria avícola mostra-se viável devido ao grande número de abates diários e ao rendimento em $\mathrm{AH}$. $\mathrm{O}$ AH extraído da crista de frango mostrou forte atividade antioxidante in vitro.

\section{REFERÊNCIAS}

AI, H. et al. Preparation and biological activities of chitosan from the larvae of housefly, Musca domestica. Carbohydrate Polymers, San Diego, v.72, n.3, p.419-423, 2007.

ALBERTINI, R. et al. The effect of glycosaminoglycans and proteoglycans on lipid peroxidation, International Journal Mollecular Medicine, Athens, v.6, n.2, p.129-136, 2000.
BALAZS, E. et al. $\mathrm{C}^{14}$ Assays and autoradiografic studies on the rooster comb. Journal Biophysica and Biochemistry Cytology, Baltimore, v.5, n.2, p.329-326, 1958.

BEEK, M. et al. Hyaluronic acid containing hydrogels for the reduction of protein adsorption. Biomaterials, Orlando, v.29, n.7, p.780-789, 2008.

BRAULE, R. Estatística aplicada com Excel para cursos de administração e economia. S. Paulo: Campus, 2001, $199 \mathrm{p}$.

CAMPO, G. et al. The antioxidant and antifibrogenic effects of the glycosaminoglycans hyaluronic acid and chodroitin-4sulphate in a subchronic rat model $\mathrm{f}$ carbon tetrachloridweinduced liver fibrogenisis. Chemico-Biological Interactions, San Diego, v.148, n.3, p.125-138, 2004.

CARDOSO, L.E. et al. A comparative analysis of glycosaminoglycans from human umbilical arteries in normal subjects and in pathological conditions affective pregnancy. Laboratory Investigation, New York, v.67, n.5, p.588-595, 1992.

DISCHE, Z. A new specific color reaction of hexuronic acids. Journal of Biological Chemistry, Maryland, v.167, n.1, p.189-198, 1946.

FRASER, J. et al. Hyaluronan: its nature, distribution, functions and turnover. Journal International Medical, Baltimore, v.242, n.1, p.27-33, 1997.

IBGE - INSTITUTO BRASILEIRO DE GEOGRAFIA E ESTATÍSTICA. Abate de animais, produção de leite, couro e ovos. 2008. Capturado em 23 de abril de 2008. Online. Disponível na Internet em: http://www.ibge.gov.br/home/ estatistica/indicadores/agropecuaria/producaoagropecuaria/ abate_leite_couro_ovos_200704_1.shtm 
KNATT, S. et al. Chitosan and mint misture: A new preservative for meat and meat products. Food Chemistry, Nova York, v.107, n.2, p.845-852, 2008.

MOI, R.C. Envelhecimento do sistema tegumentar: revisão sistemática da literatura. 2004. 85f. Dissertação (Mestrado em Enfermagem) - Programa de Pós-graduação em Enfermagem, Universidade de São Paulo, Ribeirão Preto.

NAKANO, T. et al. A simple rapid method to estimate hyaluronic acid concentration in rooster comb and wattle using cellulose acetato eletrophoresis. Journal of Agricultural and Food Chemistry, California, v.42, n.12, p.2766-2768, 1994.

NAKANO, T.; SIM, J.S. Chemical composition of glycosaminoglycan fractions from the comb and wattle of single comb white leghorn roosters. Poultry Science, California, v.70, n.12, p.2524-2528, 1991.

NAKANO, T.; SIM, S. Glycosaminoglycans from the rooster comb and wattle. Poultry Science, California, v.68, n.9, p.1303-1306, 1989.

NUNES, R. et al. Valores energéticos de subprodutos de origem animal para aves. Revista Brasileira de Zootecnia, Viçosa, v.34, n.4, p.1217-1224, 2005.
OGRODOWSKI, C.S. Produção de ácido hialurônico Streptococcus: estudo da fermentação e caracterização do produto. 2006. 121f. Tese (Doutorado em Engenharia Química) - Programa de Pós-graduação em Engenharia Química, Universidade Estadual de Campinas.

Olivo, R.; OLIVO, N. O mundo das carnes: ciência, tecnologia \& mercado. 3.ed. Criciúma: edição do autor, 2006. 209 p.

PEREIRA, I.A. Terapêutica da osteoartrose. Revista Brasileira de Reumatologia, São Paulo, v.42, n.1, p.77-82, 2002 .

SWANN, D. Studies on hyaluronic acid I. The preparation and properties of rooster comb. Biochimica et Biophysica Acta, USA, v.156, n.1, p.17-30, 1968.

SZIRMAI, J.A. Studies on the connective tissue of the cock comb. I. Histochemical observations on the ground substance. Journal Histochemistry Cytochemistry, Washington, v.4, n.2, p.96-106, 1956.

$\mathrm{XU}, \mathrm{F}$. et al. The haemocompatibility of polyurethanehyaluronic acid copolymers. Biomaterials, Tokyo, v.29, n.2, p.150-160, 2008. 